\title{
Diferentes doses de tramadol em cães: ações analgésicas, sedativas e sobre o sistema cardiorrespiratório
}

\author{
Different doses of tramadol in dogs: analgesic, sedative and cardiopulmonary effects
}

\section{Rodrigo Jesus Paolozzi ${ }^{\mathrm{I}}$ Renata Navarro Cassu ${ }^{\mathrm{II}}$ Fernando Silvério Ferreira da Cruz Letícia Rodrigues Parrilha ${ }^{\mathrm{I}}$}

RESUMO

\begin{abstract}
Objetivou-se comparar os efeitos cardiorrespiratório, analgésico e sedativo de diferentes doses de tramadol em cadelas submetidas à ovariosalpingohisterectomia (OSH). Foram avaliadas 24 cadelas SRD, adultas, distribuídas aleatoriamente em três grupos de oito animais, tratados com tramadol pela via intravenosa (IV) nas doses de 1, 2 e 4mg $\mathrm{kg}^{-1}$ (T1, T2 e T4, respectivamente). Na medicação pré-anestésica, foi

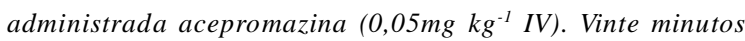
após, a anestesia foi induzida com propofol $\left(4 \mathrm{mg} \mathrm{kg}^{-1} \mathrm{IV}\right)$, com posterior manutenção anestésica com isofluorano. $O$ tramadol foi administrado 5 minutos antes da incisão cirúrgica em todos os tratamentos. Foram mensurados: frequência cardíaca, frequência respiratória, temperatura retal, pressão arterial sistólica, grau de analgesia, grau de sedação, concentração sérica de cortisol e efeitos adversos. Mínimas alterações cardiorrespiratórias foram observadas, sem diferença entre os tratamentos. O cortisol, o grau de sedação e o grau de analgesia não variaram entre os tratamentos, com exceção da terceira hora pós-cirúrgica, em que menores escores de dor foram observados no T4. Vômito foi observado em $50 \%$ dos animais do T4. Conclui-se que as diferentes doses de tramadol induziram efeitos analgésicos semelhantes, com discreto efeito sedativo $e$ mínimas alterações cardiorrespiratórias. Paralelamente, a dose de $4 m \mathrm{~m}^{-1}$ de tramadol induziu alta incidência de vômito em cadelas submetidas à $\mathrm{OSH}$.
\end{abstract}

Palavras-chave: opioide, analgesia, cortisol, ovariosalpingohisterectomia, canina.

\begin{abstract}
The aim of this study was compare the cardiopulmonary, analgesic and sedative effects of different doses of tramadol in bitches undergoing to ovariohysterectomy. Twenty four adult crossbreed bitches were randomly assigned to three treatments of 8 animals and received intravenously (IV) tramadol 1, 2 or $4 \mathrm{mg} \mathrm{kg}^{-1}$ (T1, T2 and T4, respectively). Pre-anesthetic medication was acepromazine $\left(0.05 \mathrm{mg} \mathrm{kg}^{-1} \mathrm{IV}\right)$. Anesthesia was induced with propofol $\left(4 \mathrm{mg} \mathrm{kg}^{-1} \mathrm{IV}\right)$ and maintained with isoflurane delivered in oxygen. Tramadol was administered 5 minutes before surgical incision in all groups. Heart rate, respiratory rate, rectal temperature, systolic blood pressure, degree of analgesia and sedation, serum cortisol concentration and adverse effects were measured. Mild changes were observed in cardiopulmonary variables in all treatments. The pain score was lower in T4 in the $3^{\text {rd }}$ hour after surgery in relation to other treatments. Sedation degree was not different among the treatments. The serum cortisol did not differ among the groups. In conclusion, different doses of tramadol promoted similar analgesic effects, with mild sedative and cardiopulmonary effects. However, high incidence of vomiting was observed with tramadol at $4 \mathrm{mg} \mathrm{kg}^{-1}$ in bitches undergoing ovariohysterectomy.
\end{abstract}

Key words: opioid, analgesia, cortisol, ovariohysterectomy, canine.

\section{INTRODUÇÃO}

O tramadol é um opioide atípico, cujos efeitos analgésicos são mediados por mecanismos

'Curso de Medicina Veterinária, Centro Universitário de Maringá, Serviço de Clínica Médica de Pequenos Animais, Hospital Veterinário, Maringá, PR, Brasil.

"Departamento de Cirurgia e Anestesiologia Veterinária, Faculdade de Ciências Agrárias, Universidade do Oeste Paulista (Unoeste), Rodovia Raposo Tavares, Km 572, Campus II, Bairro Limoeiro, 19067-175, Presidente Prudente, SP, Brasil. E-mail: renavarro@uol.com.br. Autor para correspondência. 
opioides, noradrenérgicos e serotoninérgicos (MCMILLAN et al., 2008). A biotransformação hepática do tramadol resulta em vários metabólitos, porém apenas um deles, O-desmetil tramadol (M1), apresenta propriedades analgésicas. Esse metabólito tem 2 a 4 vezes a potência analgésica do composto padrão, além de afinidade de 4 a 200 vezes maior para o receptor $\mu$ (LINTZet al., 1998).

Estudos desenvolvidos no homem têm relatado efeitos analgésicos satisfatórios com o uso do tramadol (SUDHEER et al., 2007; JIA et al., 2010), porém ainda há controvérsias na literatura em relação ao seu potencial analgésico para a espécie canina. Estudo realizado em cães demonstrou resultados analgésicos semelhantes, com a administração intravenosa (IV) de $2 \mathrm{mg} \mathrm{kg}^{-1}$ de tramadol e de $0,2 \mathrm{mg}$ $\mathrm{kg}^{1}$ de morfina para o tratamento da dor aguda póscirúrgica (MASTROCINQUE \& FANTONI, 2003). Resultados divergentes foram relatados por KONGARA et al. (2010), que observaram efeitos antinociceptivos inferiores com a administração (IV) de $3 \mathrm{mg} \mathrm{kg}^{-1}$ de tramadol em relação a $0,5 \mathrm{mg} \mathrm{kg}^{-1}$ de morfina.

O objetivo do presente estudo foi avaliar os efeitos cardiorrespiratório, analgésico e sedativo de diferentes doses de tramadol administrado por via intravenosa em cadelas, submetidas à ovariosalpingohisterectomia (OSH).

\section{MATERIAL E MÉTODOS}

Foram avaliadas 24 cadelas, adultas, SRD, com peso de $15 \pm 5 \mathrm{~kg}$, clinicamente saudáveis, provenientes da rotina hospitalar da instituição de origem, encaminhadas para OSH eletiva. Os animais foram selecionados para a pesquisa após constatar a ausência de alterações nos exames físico e laboratorial (hemograma, uréia e creatinina).

Após jejum sólido e hídrico de 12 e 3 horas, respectivamente, todos os animais receberam acepromazina $0,2 \%$ a $\left(0,05 \mathrm{mg} \mathrm{kg}^{-1}, \mathrm{IV}\right)$. Vinte minutos após, foi realizada a cateterização da veia cefálica direita e, em seguida, procedeu-se à indução anestésica com propofol $^{\mathrm{b}}\left(4 \mathrm{mg} \mathrm{kg}^{-1}, \mathrm{IV}\right)$. Ato contínuo, foi realizada a intubação endotraqueal, com conexão da sonda ao circuito anestésico valvular semi-fechado ${ }^{\mathrm{c}}$, pelo qual foi fornecido oxigênio a $100 \%$ (1L min $\left.{ }^{-1}\right)$ e manutenção anestésica com isofluorano ${ }^{d}$, sob ventilação espontânea. A concentração de isofluorano foi mantida entre 1,5 a $2,5 \mathrm{~V} \%$, ajustada em vaporizador calibrado, visando à manutenção dos animais no segundo plano do III estágio anestésico de Guedel, avaliado em função da estabilidade das variáveis cardiorrespiratórias (FC, PAS e $f$ ), posição do globo ocular (rotacionado), ausência de reflexo palpebral, laringotraqueal e interdigital (HASKINS, 2007). Fluidoterapia com Ringer lactato $\left(10 \mathrm{~mL}^{-1} \mathrm{~kg}^{-1} \mathrm{~h}^{-1}\right)$ e aquecimento com colchão térmico ${ }^{\mathrm{f}}$ foram mantidos durante todo o procedimento cirúrgico. Quinze minutos após a indução anestésica, oito cães de cada grupo, em estudo cego, foram aleatoriamente tratados com 1, $2{\mathrm{e} 4 \mathrm{mg} \mathrm{kg}^{-1} \text { de tramadol }}^{\mathrm{g}}$ (T1, T2 e T4, respectivamente), que foi diluído em solução salina, em volume final de $2 \mathrm{~mL}$, sendo administrado IV, em período de 60 segundos.

Foram avaliados: frequência cardíaca (FC), mediante eletrocardiografia $(E C G)^{\mathrm{h}}$; pressão arterial sistólica (PAS), pelo método não invasivo com Doppler vascular $^{\mathrm{i}}$, pela adaptação do manguito no membro torácico direito, respeitando-se uma relação de 0,4 entre a largura do manguito e a circunferência do membro; frequência respiratória $(f)$, mediante a observação dos movimentos torácicos em um minuto; temperatura retal (T), pela introdução do termômetro digital ${ }^{\dagger}$ na ampola retal, durante 2 minutos; variáveis hemogasométricas ${ }^{\mathrm{k}}$ $\left(\mathrm{PaCO}_{2}, \mathrm{pHe} \mathrm{HCO}_{3}^{-}\right)$, mediante colheita de sangue por punção da artéria femoral.

Essas variáveis foram avaliadas antes do procedimento anestésico (Basal), 15 minutos após a MPA e aos 5 e 10 minutos após a indução anestésica. Novas mensurações foram realizadas a cada 10 minutos, durante todo o procedimento cirúrgico. Com exceção da hemogasometria que foi feita cinco e 30 minutos após a indução anestésica.

A concentração sérica de cortisol foi avaliada por radioimunoensaio de fase sólida ${ }^{1}$, mediante colheita de sangue da veia cefálica esquerda, que foi cateterizada durante o procedimento anestésico. As colheitas foram realizadas antes da MPA (Basal), 15 minutos após o início da cirurgia, ao término da cirurgia, 3, 6e 12 horas após a cirurgia.

O grau de analgesia foi avaliado 1, 3, 6 e 12 horas após o término da cirurgia, utilizando-se escala de avaliação composta (Tabela 1). Em casos de somatória de escore igual ou superior a seis foi administrada analgesia complementar com tramadol (2mg kg ${ }^{-1}$, intramuscular). O grau de sedação foi avaliado nos mesmos momentos de aferição do grau de analgesia, por meio de um sistema de escore (Tabela 1). Os graus de analgesia e de sedação foram avaliados pelo mesmo observador que desconhecia a qual tratamento o animal pertencia.

Foram registrados também o tempo de cirurgia, o de extubação e o de recuperação pósanestésica (momento em que os animais foram capazes de recuperar a posição quadrupedal), além da ocorrência de efeitos adversos como náuseas, vômito, tremores, excitação e sialorréia.

Ciência Rural, v.41, n.8, ago, 2011. 
Tabela 1 - Critérios utilizados para avaliar o grau de analgesia e de sedação.

\begin{tabular}{|c|c|c|}
\hline Grau de analgesia & Critério & Pontuação \\
\hline \multirow[t]{4}{*}{$\mathrm{FC}, f, \mathrm{PAS}$} & $</=10 \%>$ que o valor pré-operatório & 0 \\
\hline & 11 a $30 \%$ > que o valor pré-operatório & 1 \\
\hline & 31 a $50 \%$ > que o valor pré-operatório & 2 \\
\hline & $50 \%>$ que o valor pré-operatório & 3 \\
\hline \multirow[t]{2}{*}{ Salivação } & Normal & 0 \\
\hline & Acima do normal & 1 \\
\hline \multirow[t]{2}{*}{ Pupila } & Normal & 0 \\
\hline & Dilatadas & 1 \\
\hline \multirow[t]{3}{*}{ Vocalização } & Sem vocalização & 0 \\
\hline & Vocalização presente controlada sem medicação & 1 \\
\hline & Vocalização presente não controlada & 2 \\
\hline \multirow[t]{4}{*}{ Agitação } & Adormecido ou calmo & 0 \\
\hline & Leve agitação & 1 \\
\hline & Moderada agitação & 2 \\
\hline & Severa agitação & 3 \\
\hline \multirow[t]{2}{*}{ Postura } & Decúbito esternal ou movendo-se com tranquilidade & 0 \\
\hline & Defendendo e protegendo a área afetada, incluindo posição fetal ou decúbito lateral & 1 \\
\hline \multirow[t]{4}{*}{ Resposta a manipulação } & Sem Resposta & 0 \\
\hline & Resposta mínima, tenta esquivar-se & 1 \\
\hline & Vira a cabeça em direção à ferida cirúrgica, leve vocalização & 2 \\
\hline & Vira a cabeça com intenção de morder, severa vocalização & 3 \\
\hline \multicolumn{3}{|l|}{ Grau de sedação } \\
\hline & Animal acordado se mantém em pé e caminha & 0 \\
\hline & Mantém-se em pé, mas incoordenado & 1 \\
\hline & Tenta, mas não consegue se manter em pé & 2 \\
\hline & Mantém a cabeça levantada & 3 \\
\hline & Somente abre os olhos & 4 \\
\hline & Sem resposta & 5 \\
\hline
\end{tabular}

Fonte: PIBAROT et al. (1997). FC: frequência cardíaca, $f$ : frequência respiratória, PAS: pressão arterial sistólica.

No pós-operatório, foi realizada antibioticoterapia com enrofloxacina $\mathrm{m}^{\mathrm{m}}\left(5 \mathrm{mg} \mathrm{kg}^{-1} \mathrm{BID}\right) \mathrm{e}$ curativo local, durante 10 dias, além de meloxicam ${ }^{\mathrm{n}}$ $\left(0,1 \mathrm{mg} \mathrm{kg}^{-1} \mathrm{SID}\right)$, durante 5 dias, cuja primeira dose foi administrada somente após a última aferição do efeito analgésico.

Foi utilizada análise de variância (ANOVA) para comparação entre os grupos, com contrastes verificados pelo teste de Tukey. Para comparar os momentos dentro de cada grupo, foi utilizada ANOVA para amostras relacionadas, com contrastes verificados pelo teste de Tukey. Adotou-se nível de significância de 5\% (ZAR, 1996).

\section{RESULTADOS}

A FC não diferiu entre os tratamentos, porém no T1 foi observada redução 15 minutos após a MPA em relação aos valores basais. No T2, a FC diminuiu aos 10 e 20 minutos após a indução anestésica, enquanto no $\mathrm{T} 4$ a mesma diferença foi observada 15 minutos após a MPA, aos 5, 10, 20 e 30 minutos após a indução anestésica. A $f$ e a PAS não diferiram entre os tratamentos, porém foi observada redução aos 5, 10, 20 e 30 minutos após a indução anestésica em relação aos valores basais em ambos os parâmetros nos três grupos. A temperatura retal e as variáveis hemogasométricas não diferiram entre os tratamentos e nem ao longo do tempo (Tabela 2).

$\mathrm{Na}$ avaliação da dor, escores inferiores foram observados na 3 a hora de avaliação no T4 em relação aos demais tratamentos (Tabela 3 ). Analgesia de resgate não foi necessária em nenhum dos animais avaliados.

O grau de sedação não difereriu entre os tratamentos, no entanto, escores inferiores foram observados na $6^{\mathrm{a}}$ e $12^{\mathrm{a}}$ horas em relação à $1^{\mathrm{a}} \mathrm{e}$ e $3^{\underline{a}}$ horas pós-cirúrgicas (Tabela 3).

Ciência Rural, v.41, n.8, ago, 2011. 
Tabela 2 - Valores médios e desvio padrão da frequência cardíaca (FC), frequência respiratória (f), pressão arterial sistólica (PAS), temperatura retal $(\mathrm{T})$, pressão parcial de dióxido de carbônico $\left(\mathrm{PaCO}_{2}\right)$, concentração hidrogeniônica $(\mathrm{pH})$ e bicarbonato $\left(\mathrm{HCO}_{3}^{-}\right)$ no sangue arterial de cadelas tratadas por via intravenosa com tramadol 1, 2 e $4 \mathrm{mg} \mathrm{kg}^{-1}$ (T1, T2 e T4, respectivamente).

\begin{tabular}{|c|c|c|c|c|c|c|}
\hline & Basal & 15'MPA & $5^{\prime}$ & $10^{\prime}$ & $20^{\prime}$ & $30^{\prime}$ \\
\hline \multicolumn{7}{|r|}{---------- } \\
\hline $\mathrm{T} 1$ & $119 \pm 34$ & $94 \pm 8^{*}$ & $107 \pm 15$ & $103 \pm 20$ & $104 \pm 15$ & $110 \pm 13$ \\
\hline $\mathrm{T} 2$ & $121 \pm 18$ & $108 \pm 18$ & $108 \pm 16$ & $92 \pm 18^{*}$ & $97 \pm 17^{*}$ & $107 \pm 18$ \\
\hline $\mathrm{T} 4$ & $122 \pm 18$ & $99 \pm 20^{*}$ & $95 \pm 14 *$ & $95 \pm 19^{*}$ & $95 \pm 18^{*}$ & $95 \pm 19^{*}$ \\
\hline $\mathrm{T} 1$ & $30 \pm 10$ & $26 \pm 9$ & $15 \pm 6^{*}$ & $15 \pm 5^{*}$ & $12 \pm 3 *$ & $14 \pm 3 *$ \\
\hline $\mathrm{T} 2$ & $28 \pm 9$ & $24 \pm 8$ & $14 \pm 2 *$ & $16 \pm 4 *$ & $16 \pm 3^{*}$ & $15 \pm 3^{*}$ \\
\hline $\mathrm{T} 4$ & $32 \pm 12$ & $24 \pm 11$ & $13 \pm 3 *$ & $14 \pm 3^{*}$ & $13 \pm 4 *$ & $13 \pm 2 *$ \\
\hline $\mathrm{T} 1$ & $126 \pm 7$ & $123 \pm 16$ & $93 \pm 10^{*}$ & $110 \pm 9^{*}$ & $111 \pm 9^{*}$ & $105 \pm 8^{*}$ \\
\hline $\mathrm{T} 2$ & $130 \pm 10$ & $124 \pm 9$ & $95 \pm 6^{*}$ & $112 \pm 5$ & $117 \pm 11^{*}$ & $113 \pm 9 *$ \\
\hline $\mathrm{T} 4$ & $118 \pm 8$ & $115 \pm 10$ & $85 \pm 10^{*}$ & $105 \pm 10^{*}$ & $100 \pm 10^{*}$ & $103 \pm 9^{*}$ \\
\hline \multicolumn{7}{|c|}{$\mathrm{T}^{\circ} \mathrm{C}$} \\
\hline $\mathrm{T} 1$ & $38,7 \pm 0,4$ & $38,7 \pm 0,3$ & $37,8 \pm 0,5$ & $37,6 \pm 0,4$ & $37,4 \pm 0,4$ & $37,2 \pm 0,4$ \\
\hline $\mathrm{T} 2$ & $38,8 \pm 0,5$ & $38,7 \pm 0,8$ & $38 \pm 0,5$ & $38 \pm 0,5$ & $37,8 \pm 0,5$ & $37,6 \pm 0,6$ \\
\hline $\mathrm{T} 4$ & $38,8 \pm 0,4$ & $38,7 \pm 0,4$ & $38,1 \pm 0,4$ & $37,6 \pm 0,6$ & $37,4 \pm 0,6$ & $37,5 \pm 0,6$ \\
\hline & \multirow{2}{*}{\multicolumn{5}{|c|}{$39 \pm 3$}} & \\
\hline $\mathrm{T} 1$ & & & & & & $39,5 \pm 12$ \\
\hline $\mathrm{T} 2$ & \multicolumn{5}{|c|}{$42 \pm 6$} & $41 \pm 7$ \\
\hline $\mathrm{T} 4$ & \multicolumn{5}{|c|}{$42 \pm 8$} & $36 \pm 7$ \\
\hline $\mathrm{T} 1$ & \multicolumn{6}{|c|}{-pH (unidades) -- } \\
\hline $\mathrm{T} 2$ & \multicolumn{5}{|c|}{$7,33 \pm 0,04$} & $7,37 \pm 0,08$ \\
\hline $\mathrm{T} 4$ & \multicolumn{5}{|c|}{$7,34 \pm 0,05$} & $7,34 \pm 0,07$ \\
\hline & \multicolumn{6}{|c|}{$-\mathrm{HCO}_{3}^{-}\left(\mathrm{mEq} \mathrm{1}^{-1}\right)$} \\
\hline $\mathrm{T} 1$ & \multicolumn{5}{|c|}{$21,7 \pm 2$} & $21 \pm 2$ \\
\hline $\mathrm{T} 2$ & \multicolumn{5}{|c|}{$21,8 \pm 3$} & $21 \pm 2$ \\
\hline $\mathrm{T} 4$ & \multicolumn{5}{|c|}{$22,3 \pm 4$} & $21,2 \pm 4$ \\
\hline
\end{tabular}

*P $<0,05$ : redução significativa em relação ao basal; ${ }^{\#} \mathrm{P}<0,05$ : aumento significativo em relação aos 5 minutos após a indução anestésica. 5', 10’, 20', 30’ = minutos após indução anestésica.

O cortisol sérico não variou entre os tratamentos, contudo foi superior quando comparado aos valores basais aos 15 minutos após o início da OSH e ao seu término em todos os tratamentos. No período pós-operatório, o cortisol foi superior em

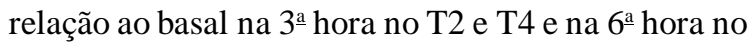
T4 (Tabela 3).

Efeitos adversos não foram evidenciados em nenhum dos tratamentos, com exceção da ocorrência de vômito que foi observada entre a $1^{\text {a }}$ e a $3^{\underline{a}}$ hora póscirúrgicas em 50\% (4/8) dos animais do T4.

O tempo cirúrgico $(30 \pm 9,28 \pm 12$ e $32 \pm 6$ minutos no T1, T2 e T4, respectivamente), o tempo de extubação $(4 \pm 1,6 \pm 3$ e $7 \pm 4$ minutos no T1, T2 e T4, respectivamente) e o tempo de recuperação pósanestésica $(24 \pm 5,28 \pm 4$ e $30 \pm 4$ minutos no T1, T2 e T4, respectivamente) não diferiram entre os tratamentos.

\section{DISCUSSÃO}

Os resultados do presente estudo sugerem que os diferentes tratamentos com tramadol proporcionaram analgesia semelhante entre os grupos, com exceção da 3 a hora pós-operatória, momento em que os animais do $\mathrm{T} 4$ exibiram os menores escores de dor. No entanto, esse achado não apresentou relevância clínica, visto que, em todos os tempos avaliados, os escores de dor mantiveram-se bem inferiores ao limite de 6 , que seria o escore mínimo para a realização de analgesia suplementar. Dessa forma, nenhum animal necessitou de analgesia de resgate durante o período de 12 horas, concordando com os resultados obtidos em estudo semelhante realizado em cães, no qual, durante o período de 8 horas, nenhum analgésico suplementar foi necessário (VETTORATO et al., 2010).

Ciência Rural, v.41, n.8, ago, 2011. 
Tabela 3 - Valores médios e desvio padrão da concentração sérica de cortisol, dos escores de dor e de sedação em cadelas tratadas por via intravenosa com tramadol 1,2 e $4 \mathrm{mg} \mathrm{kg}^{-1}$ (T1, T2 e T4, respectivamente).

\begin{tabular}{|c|c|c|c|c|c|c|c|}
\hline & Basal & $15^{\prime} \mathrm{OSH}$ & Fim OSH & $1 \mathrm{~h}$ & $3 \mathrm{~h}$ & $6 \mathrm{~h}$ & $12 \mathrm{~h}$ \\
\hline & & 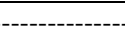 & --Cortiso & 1) ------- & ---------- & ------- & ---------- \\
\hline $\mathrm{T} 1$ & $4,4 \pm 4$ & $10,6 \pm 6^{*}$ & $11,5 \pm 6^{*}$ & ------ & $8 \pm 4$ & $5,7 \pm 2$ & $3,6 \pm 1$ \\
\hline $\mathrm{T} 2$ & $3,4 \pm 2$ & $7,3 \pm 3 *$ & $8,6 \pm 2 *$ & ------- & $7,5 \pm 2 *$ & $5,0 \pm 3$ & $4,1 \pm 0,9$ \\
\hline $\mathrm{T} 4$ & $3,7 \pm 1,5$ & $6,9 \pm 2 *$ & $8,5 \pm 3^{*}$ & ------- & $8,1 \pm 4 *$ & $6,4 \pm 2 *$ & $3,9 \pm 0,7$ \\
\hline $\mathrm{T} 1$ & & & & $2,5 \pm 1,3$ & $2,6 \pm 1,7$ & $2,4 \pm 1,6$ & $2,4 \pm 1,6$ \\
\hline $\mathrm{T} 2$ & & & & $2,6 \pm 1,5$ & $1,3 \pm 1$ & $1,4 \pm 1$ & $1,9 \pm 1,4$ \\
\hline $\mathrm{T} 4$ & & & & $1,3 \pm 0,7$ & $0,8 \pm 0,5^{\#}$ & $1,4 \pm 0,8$ & $1,8 \pm 1,3$ \\
\hline $\mathrm{T} 1$ & & & Do. & $2,2 \pm 1,1$ & $1,9 \pm 1$ & $1,1 \pm 1,2^{?}$ & $0,3 \pm 0,7^{?}$ \\
\hline $\mathrm{T} 2$ & & & & $2,1 \pm 0,8$ & $1,8 \pm 1$ & $0,1 \pm 0,2^{?}$ & $0 \pm 0^{?}$ \\
\hline $\mathrm{T} 4$ & & & & $2,9 \pm 1,3$ & $2,1 \pm 1$ & $1,1 \pm 1,3^{?}$ & $0,1 \pm 0,4^{?}$ \\
\hline
\end{tabular}

* $\mathrm{P}<0,05$, aumento significativo em relação aos valores basais. ${ }^{*} \mathrm{P}<0,05$ : redução significativa em $\mathrm{T} 4$ em relação ao $\mathrm{T} 1$ e $\mathrm{T} 2$. ? $\mathrm{P}<0,05$ : redução significativa em relação à $1^{\mathrm{a}}$ e $3^{3}$ h h pós-cirúrgica.

15’OSH: 15 minutos após o início do procedimento cirúrgico; Fim OSH: ao término do procedimento cirúrgico; 1h, 3h, 6h, 12h: após o procedimento cirúrgico.

A avaliação da dor em animais é um desafio, em função da impossibilidade da expressão verbal, bem como pela variabilidade da resposta comportamental de cada paciente. Dessa forma, muitos estudos têm sido conduzidos com a proposta de diferentes métodos para a avaliação da dor (escalas analógicas visuais, escalas numéricas, escalas descritivas e compostas), buscando minimizar os possíveis equívocos no seu diagnóstico (MASTROCINQUE \& FANTONI, 2003; VETTORATO et al., 2010).

O método empregado para avaliação da dor no presente estudo já foi descrito previamente por outros autores em pesquisas semelhantes desenvolvidas em cães (PIBAROT et al., 1997; ALMEIDA et al. 2010). Todavia, independente da metodologia empregada para o diagnóstico da dor, efeito analgésico favorável tem sido relatado em cães tratados com o emprego do tramadol (IV) na dose de $2 \mathrm{mg} \mathrm{kg}^{-1}$ (MASTROCINQUE \& FANTONI, 2003; VETTORATO et al., 2010; MARTINS et al., 2010). Em cadelas avaliadas mediante escalas descritiva numérica e analógica visual, foi demonstrado efeito analgésico semelhante com o uso de tramadol $\left(2 \mathrm{mg} \mathrm{kg}^{-1}\right)$ ou morfina $\left(0,2 \mathrm{mg} \mathrm{kg}^{-1}\right)$, sugerindo que ambos os tratamentos conferem analgesia adequada para o alívio da dor decorrente da OSH. Em estudo semelhante, porém com o emprego da Escala Composta de Glasgow para a avaliação da dor, VETTORATO et al. (2010) relataram analgesia favorável durante as primeiras 8 horas de avaliação após OSH, com baixos escores de dor em todos os animais avaliados. Em cães, cuja dor foi avaliada com escala numérica e descritiva, encaminhados para mandibulectomia ou maxilectomia, o tratamento com tramadol $\left(2 \mathrm{mg} \mathrm{kg}^{-1}\right)$ isolado ou associado ao cetoprofeno resultou em efeito analgésico adequado, com mínima necessidade de suplementação analgésica nas primeiras 24 horas após a cirurgia (MARTINS et al., 2010). Dessa forma, apesar de os estudos farmacocinéticos desenvolvidos no cão relatarem baixas concentrações do metabólito M1 (LINTZ et al., 1998; MCMILLAN et al., 2008), além de curto período de ação do tramadol, com meia vida de eliminação inferior à observada na espécie humana (KUKANICK \& PAPICK, 2004), os resultados provenientes das pesquisas clínicas com o uso deste opioide para o controle da dor aguda pós-operatória têm demonstrado resultados promissores, com efetivo alívio do desconforto pós-cirúrgico, em casos de dor discreta a moderada.

No entanto, não há estudos publicados com o emprego de outras doses de tramadol (IV) para o tratamento da dor aguda pós-operatória no cão. ALMEIDA et al. (2010) demonstraram efeito analgésico satisfatório durante 24 horas após orquiectomia em cães com o emprego de tramadol na dose de $1 \mathrm{mg} \mathrm{kg}^{-1}$, no entanto, a via de administração empregada foi a peridural. Contudo, em estudo desenvolvido em cães, a administração peridural do tramadol resultou em efeitos farmacocinéticos, eficiência e duração analgésica semelhantes aos obtidos pela administração intravenosa (VETTORATO et al., 2010). 
Não foram encontrados dados na literatura com a administração do tramadol na dose $4 \mathrm{mg} \mathrm{kg}^{-1}$ para o tratamento da dor pós-operatória no cão. No atual estudo, o incremento da dose de tramadol, aparentemente, não promoveu efeito analgésico mais pronunciado em relação à administração das outras doses. Contudo, uma vez que as doses mais baixas já se mostraram suficientes para o alívio do desconforto proveniente da $\mathrm{OSH}$, não foi possível evidenciar diferenças entre os tratamentos. Provavelmente, em casos de respostas álgicas mais pronunciadas, decorrentes de procedimentos cirúrgicos mais invasivos, a variação do efeito analgésico em função da dose empregada poderia ser mais evidente.

O efeito sedativo observado no atual estudo foi discreto, provavelmente em função da fraca afinidade do tramadol pelo receptor $\mathrm{mu}(\mu)$ (LINTZ et al., 1998), corroborando resultados prévios que relataram sedação pouco pronunciada com o uso de tramadol em cães (MCMILLAN et al., 2008).

Com relação às concentrações séricas de cortisol, os atuais achados corroboram resultados prévios que demonstraram o incremento dos níveis séricos de cortisol devido à manipulação ovariana na espécie canina (FOX et al., 1994). O cortisol mantevese elevado em relação aos valores fisiológicos da espécie, compreendido entre 0,96 a $6,81 \mu \mathrm{g} \mathrm{dl}^{-1}$, (KANEKO et al., 1997) durante as primeiras 3 horas após a OSH, sugerindo que o tramadol (IV), independente da dose empregada, não inibiu a resposta de estresse decorrente do trauma cirúrgico. Todavia, independente da sensação de dor, a concentração de cortisol pode variar em função de outros fatores, como medo, ansiedade, tempo cirúrgico e fatores ambientais (FOX et al., 1994). No atual estudo, o tempo cirúrgico, além de não variar entre os grupos, não excedeu o tempo que normalmente é despendido para realização de OSH, com duração média de 30 minutos. No entanto, fatores incontroláveis como ansiedade e medo em função do ambiente hospitalar, bem como da contenção física necessária para a colheita de sangue possam ter contribuído para resposta de estresse (CARROLL et al., 2005).

Mínimas alterações cardiovasculares foram observadas durante a cirurgia, confirmando resultados anteriores relatados em cães (MASTROCINQUE \& FANTONI, 2003; VETTORATO et al., 2010). Tanto a FC quanto a PAS mantiveram-se estáveis durante o procedimento cirúrgico. Redução transitória da pressão arterial foi observada após a indução anestésica, em todos os tratamentos, no entanto, esse achado não teve relevância clínica, visto que tal efeito foi observado apenas antes do início do estímulo nociceptivo cirúrgico, podendo ser atribuído ao efeito vasodilatador da acepromazina, do propofol e do isofluorano (BEDNARSKI, 2007).

Estudos prévios demonstraram estabilidade na função respiratória, com o uso do tramadol no cão (MASTROCINQUE \& FANTONI, 2003; MCMILLAN et al., 2008; VETTORATO et al., 2010), confirmando os achados do presente estudo. $\mathrm{O}$ tramadol é praticamente desprovido de efeito depressor respiratório, devido à fraca interação desse fármaco ao receptor opioide $\mu$ (LINTZet al., 1998).

A recuperação pós-anestésica foi tranquila e suave em todos os tratamentos, porém alta incidência de vômito foi observada no T4, sugerindo que esse efeito possa estar relacionado ao incremento da dose, conforme relatado por KUKANICK \& PAPICK (2004). Apesar da fraca interação com o receptor opioide $\mu, o$ que confere a redução de efeitos colaterais, estudos desenvolvidos no homem têm demonstrado alta incidência (30 a 50\%) de náusea e vômito com o uso desse analgésico (SUDHEER et al., 2007; JIA et al., 2010), sobretudo após administração em bolus IV e no emprego de doses elevadas (MCMILLAN et al., 2008). Em cães, poucos estudos foram desenvolvidos com doses superiores a $2 \mathrm{mg} \mathrm{kg}^{-1}$, de modo que estudos futuros são necessários para melhor esclarecimento dos efeitos do tramadol na referida espécie.

\section{CONCLUSÃO}

A administração intravenosa de tramadol

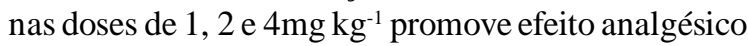
semelhante em cadelas submetidas à OSH. Paralelamente, mínimas alterações cardiorrespiratórias, discreta sedação e poucos efeitos adversos foram observados com as doses avaliadas, com exceção da alta incidência de vômito nos animais tratados com $4 \mathrm{mg} \mathrm{kg}^{-1}$ de tramadol.

\section{FONTES DE AQUISIÇÃO}

\footnotetext{
a - Acepran 0,2\%, Univet, São Paulo, SP, Brasil.

b - Propovan, Cristália, Itapira, SP, Brasil.

c - Vet Care, Brasmed, Paulínia, SP, Brasil.

d - Isofluorano, Cristália, Itapira, SP.

e - Vaporizador Calibrado, Takaoka, São Paulo, SP, Brasil.

f - Colchão térmico, Brasmed, Paulínia, SP, Brasil.

g - Tramadon, Cristália, Itapira, SP, Brasil.

h - Eletrocardiógrafo Cardiotest Ek 5, São Paulo, SP, Brasil.

i - Doppler 841-A, Parks Medical Electronics, Las Vegas, EUA.

j - Termômetro digital, Becton Dickinson, Juiz de Fora, MG, Brasil.

k - pH/Blood Gas Analyzer, model 248, Ciba Corning Diagnostics, Medfield, MA, USA

1 - Coat-A-Count Cortisol - DPC, Califórnia, CA, USA.

m - Baytril, Bayer, São Paulo, SP, Brasil.

n - Movatec, Roche, São Paulo, SP, Brasil.
} 


\section{COMITÊ DE ÉTICA}

Este estudo foi aprovado pelo Comitê de Ética em Pesquisa (CEP) da Instituição de Origem, sob o protocolo $n$. 050/2008, realizado de acordo com os princípios éticos na experimentação animal.

\section{REFERÊNCIAS}

ALMEIDA, R.M. et al. Comparison of analgeisa provided by lidocaine, lidocaine-morphine or lidocaine-tramadol delivered epidurally in dogs following orchiectomy. Veterinary Anaesthesia and Analgesia, v.37, p.542-549, 2010. Disponível em: <http://www3.interscience.wiley.com>. Acesso em: 20 jan. 2010. doi: 10.1111/j.1467-2995.2010.00563.x.

BEDNARSKI, R.M. Anesthesia, analgesia and immobilization of dogs and cats. In: TRANQUILLI, W.J. et al. Lumb \& Jones' veterinary anesthesia and analgesia. 4.ed. Oxford: Blackwell Publishing, 2007. p.705-715.

CARROLL, G.L. et al. Analgesic efficacy of preoperative administration of meloxicam or butorphanol in onychectomized cats. Journal of American Veterinary Medical Association, v.226, p.913-919, 2005.

FOX, S.M. et al. Changes in plasma cortisol concentrations before, during and after analgesia, anaesthesia plus ovariohysterectomy in bitches. Research of Veterinary Science, v.57, p.110-118, 1994.

HASKINS, S.C. Monitoring anesthetized patients. In: TRANQUILLI, W.J. et al. Lumb \& Jones' veterinary anesthesia and analgesia. 4.ed. Oxford: Blackwell Publishing, 2007. p.533-560.

JIA, D.L. et al. A small-dose naloxone infusion alleviates nausea and sedation without impacting analgesia via intravenous tramadol. Chinese Medical Journal, v.123, p.1695-1698, 2010. Disponível em: <http://www.cmj.org/ pubmed>. Acesso em: 01 dez. 2010. doi: 10.3760/cma.j.

KANEKO, J.J. et al. Clinical biochemistry of domestic animals. San Diego: Academic, 1997. 932p.

KONGARA, K. et al. Electroencephalographic responses of tramadol, parecoxib and morphine to acute noxious electrical stimulation in anaesthetised dogs. Research Veterinary Science, v.88, p.127-133, 2010.

KUKANICK, B.; PAPICH, M.G. Pharmacokinetics of tramadol and metabolite O-desmethyltramadol in dogs. Journal of Veterinary Pharmacology Therapy, v.27, p.239-246, 2004.

LINTZ, W. et al. Pharmacokinetics of tramadol and bioavailability of enteral tramadol formulations. $2^{\text {nd }}$ communication: drops with ethanol. Arzneimittelforschung, v.48, p.436-445, 1998.

MARTINS, T. et al. Comparison of the effects of tramadol, codeine, and ketoprofen alone or in combination on postoperative pain and on concentrations of blood glucose, serum cortisol, and serum interleukin-6 in dogs undergoing maxillectomy or mandibulectomy. American Journal Veterinary Research, v.71, p. 1019-1026, 2010.

MASTROCINQUE, S.; FANTONI, D.T. A comparison of preoperative tramadol and morphine for the control of early postoperative pain in bitches submitted to ovariohysterectomy. Veterinary Anaesthesia and Analgesia, v.30, p.220-228, 2003.

MCMILLAN, C.J. et al. Pharmacokinetics of intravenous tramadol in dogs. Canadian Journal Veterinary Research, v.72, p.325-331, 2008.

PIBAROT, P. et al. Comparison of ketoprofen, oxymorphone, and butorphanol in the treatment of postoperative pain in dogs. Journal American of Veterinary Medical Assocation, v.211, p.438-444, 1997.

SUDHEER, P.S. et al. Comparison of the analgesic efficacy and respiratory effects of morphine, tramadol and codeine after craniotomy. Anaesthesia, v.62, p.555-560, 2007. Disponível em: $\leq$ http://onlinelibrary.wiley.com/>. Acesso em: 01 dez. 2010. doi: 10.1111/j.1365-2044.2007.05038.x.

VETTORATO, E. et al. Pharmacokinetics and efficacy of intravenous and extradural tramadol in dogs. Veterinary Journal, v.183, p.310-315, 2010. Disponível em: <http:// www.elsevier.com/locate/tvjl>. Acesso em: 23 jan. 2009. doi: $10.1016 / j . t v j 1.2008 .11 .002$

ZAR, J. H. Biostatistical analysis. New Jersey: PrenticeHall Upper Saddle River, 1996. 718p. 